\title{
LXXVII. Experiments proving the common nature of magnetism, cohesion, adhesion and viscosity
}

\author{
Sir Graves C. Haughton K.H. M.A. F.R.S.
}

To cite this article: Sir Graves C. Haughton K.H. M.A. F.R.S. (1847) LXXVII. Experiments proving the common nature of magnetism, cohesion, adhesion and viscosity, Philosophical Magazine Series 3, 30:204, 502-522, DOI: 10.1080/14786444708645764

To link to this article: http://dx.doi.org/10.1080/14786444708645764

曲 Published online: 30 Apr 2009.

Submit your article to this journal $[\pi$

Џll Article views: 2

Q View related articles 
determined at both stations, the posterior slope exhibiting a rapid and deep fall, which took place alike at Christiania and Plymouth.

The erest No. 2 passed Cork, Belfast and the Orkneys on the 5 th, Plymouth on the 7 th, and Paris on the 8 th, with a diminution of oscillation. We find however no diminution of oscillation at Christiania as compared with Plymouth. It is highly probable the subsidence of the crest, as it proceeded towards Paris, resulted from the influence of the land in England, while both at Plymouth and Christiania the crest was but slightly interfered with by the influence of land, the difference of level resulting from the anterior slope of crest No. 3 .

These considerations exhibit a large wave of considerable breadth and slow motion, extending in a longitudinal direction from the extreme south-west of England, past Norfolk, towards the Swedish capital.

The elements of the waves, as referred to in Tables II., III., IV. and $\mathrm{V}$., have been determined by observations made daily; and a perusal of the discussion of these observations will clearly show that, in order to detect and examine the charaoters of the larger undulations, daily observations may suffice. For this purpose it will be best to choose the middle of the day. The Astronomer Royal has determined, from four years' observations at Greenwich, that at 2 hours, Göttingen mean time (20 minutes past 1 P.M. Greenwich time), the barometer varies but $0^{\mathrm{in}} .001$ from the mean of the year, that is, if the mean pressure is to be determined from an isolated observation each day, this hour is the most suitable, the mean correction being $0^{\text {in. }} 001$ to be added. This at once indicates, that for the present purpose this hour is also the most suitable, the observations being, to a great extent, free from the effects of the diurnal oscillation, If two observations are made, the most suitable epochs are $7.20 \mathrm{A.M}$. and 1.20 P.M.; and if three, 7.20 P.M, in addition. In order however to detect and examine smaller undulations, observations at shorter intervals equally disposed throughout the twentyfour hours are essential.

LXXVII. Experiments proving the common nature of Magnetism, Cohesion, Adhesion and Viscosity. By Sir Graves C. HAUGHTON, K.H., M.A., F.R.S., Foreign Associate of the Institute of France, \&c.

[Continued from p. 457.]

Part II.

Of the mutual magnetic attractions of non-ferruginous bodies.

A FTER a great number of substances had been measured according to the preceding plan, it occurred to me that by a slight modification of the needle, the mutual magnetic relations of non-ferruginous bodies might possibly be ascertained. Through the obliging readiness of $M$. Pixii of this city, I had 
two needles constructed, half of which were magnets and the other half brass; the junction of the brass and steel being effected exactly mid-way where the caps were attached. As it was anticipated that the movement of such a needle would be slow, as the whole directive energy could only be obtained from the magnetic end, their caps were of stone. I had the pleasure to find that though their movement was necessarily sluggish in comparison with that of the common needle, yet that it was perfectly uniform and certain; and that the brass end attached itself to various substances with even more tenacity than had been the case with the purely magnetic needle, or with its own magnetic portion. I next had two needles made, one with a gold and the other with a silver termination; but owing to a misapprehension of the workman their caps were of brass, and from this circumstance the increased friction prevented their free movement, particularly in the case of the silver needle. However, sufficient was discovered by their employment to see that the gold and silver could likewise be made to attach themselves to non-ferruginous bodies.

It was only now necessary to make such a modification of the new principle of measurement as should enable it to be applied to any metal, and for this purpose I had short tubes soldered to the ends of half magnetic needles where they were joined to their agate caps. Into these small tubes needles of any malleable metal could be inserted at pleasure; their weight and length being just sufficient to balance the steel portion of the needles. The steel ends were necessarily made thicker than the magnetic needle I have already described, to balance the increased weight of the tubes and metal needles; and the whole weighed, when complete, in one case sixteen grains, and in the orher, which was a little larger, nearly eighteen grains. The length of the steel half was twenty-three millimètres, and the whole needle therefore forty-six millimètres long. It is necessary to bear in mind that the metal needles should not exceed the magnetic ends in length, otherwise, according to the principle of the lever, they would be moved with greater facility than the steel portion, and give proportionably higher results.

The form of these needles is here given with and without their metal ends.
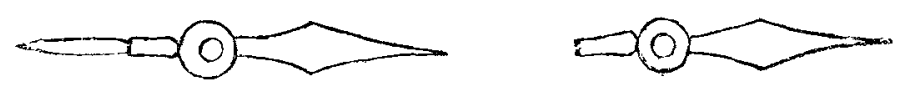

By a further modification, the arrangement was fitted to be 
employed with any small fragment or substance that it was desirable to use as a needle. This consisted simply in making a slender needle of wood of the same form as those of metal, by means of which any fragment, though not exceeding the size of the head of a pin, could be attached with wax, and then employed, the same as if it were a needle of malleable metal, after being inserted in the little tube of the magnetic needle. The deficient weight of the wooden needle can be made up by twining round it a fine strip of sheetlead; and in like manner the metal needles may be made to balance with equal nicety, when too light, by rolling round them a small strip of tin foil; a necessity that must often occur, owing to the different densities of the metals employed. All these details are requisite, as the experimenter must in so many cases become his own workman, to meet each particular exigency.

These needles were urged to the substances by a bar-magnet, in the same way as in the preceding experiments, and were employed either in measuring the purely magnetic intensities or those of non-ferruginous bodies, by using one or the other end as occasion required. The unmagnetic ends were likewise made to connect themselves with substances, for which they had a strong affinity, by means of the finger instead of a bar-magnet as in the former cases, but to a much greater extent, for it was the only means I had at my command of ascertaining that the junction was made with more than usual readiness, and this result is here marked by the letter $f$, instead of the signs $\times \times$ as before. All the other signs formerly used are again employed in similar cases, and it will be seen, perhaps with some surprise, that the mutual affinities of non-ferruginous bodies greatly exceed those of the magnetic needle, there being few cases in which the measures did not reach $90^{\circ}$.

In the preceding branch of this subject, whatever has been said on the importance of giving time for the influence of the needle to take effect, is no longer necessary; and all that is required is to afford the time requisite for oscillation entirely to cease; for here the effects are purely normal, as non-ferruginous bodies only are mutually concerned. This result might have been easily anticipated, for it is now merely natural and spontaneous affinities that are brought into play. Magnetism, in the common acceptation of the term, will be seen to be an abnormal and exceptional state, and all the results that proceed from it must partake of the same character. The more powerful therefore the magnet or the loadstone, the more abnormal and exceptional must be its results. 
The phænomena brought to light by Dr. Faraday's mode of experimenting are indeed very remarkable, and they ap. pear to me to have a surprising analogy with what he and Thilourier effected, when operating on the gases. By the resources of science, those bodies which in their normal state only exhibit repulsion, were made to reveal their occult power of attraction; and in a similar manner in these new experiments, bodies that had been only remarked for indifference to magnetism, were brought within its pale. Yet the instances which $I$ have already shown, and those which are to follow, will make it more than doubtful whether the two categories of attraction and repulsion under which bodies arranged themselves in his hands, are really those that would result from their normal conditions, if these could be known with exactness. Thus by his experiments he considers platinum as magnetic, and flint glass as diamagnetic, and they ought not therefore to agree in their affinities; yet I find that they both have a remarkable attraction for lead; crown glass too, so far from having a feeble attraction for the magnet, as we are led to suppose from his experiments, has really a very considerable affinity for it, as will be evident by the instance I gave of the needle in the compass-box, which attached itself per saltum to its glass screen on a magnet being held over it. Palladium and platinum also, which Dr. Faraday considers as magnetic, agree with all his diamagnetic metals with which I have operated in their attraction for glass of every kind, and I find that both palladium and platinum exhibit a much feebler degree of attraction for the magnetic needle than they do for iron that is free from magnetism. Yet in his scale crown glass ranges between palladium and platinum.

The obscure nature of affinity cannot be better exemplified than in considering these experiments, where we have a fresh demonstration of its universality. As no instance has yet been discovered of a body existing free from repulsion, for no bodies have yet been found with their molecules in close contact, so in the present case we shall see that where attraction could not be more than imagined, that that property exists in considerable strength, and that it is owing to it, by the mere affinity of points for points, that is of molecules for molecules, that bodies hold together with such tenacity, though each point is totally inert beyond its own sphere of action; indeed so much so that the finest hair or a fragment of any substance not so large as the head of a pin, has as much influence, magnetically, on the various needles that have been tried, as the largest mass. It is different however where the electromagnet is concerned, for through its powerful influence the 
magnetic energies of bodies brought within its range are heightened to a surprising degree. Magnetism proves the co-existing and alternating nature of attraction and repulsion, and that where we tind one we may be quite certain that the other is only in abeyance, existing potentially, and ready to spring into action the moment the conditions of bodies are such as to admit of this law of nature coming into activity. I say bodies, because, as it is a law of relation, there must be the mutual presence of two things to enable it to exist. Now the insensible relations which the present experiments reveal, seem identical with those which Dr. Faraday was able to make sensible, even to an audience in a theatre, by the means of a powerful electro-magnet, just in the same way as when a bit of paper excited positively or negatively, and scarcely affording the slightest indication of its excitement, will be roused into strong repulsion by the approach of any electric body in a similar state with itself, but more highly excited; and indeed the degree of its repulsion will be proportioned to the energy of the electric state of the body with which it is in relation; it being one of the mysterious peculiarities of affinity that the body that exhibits it in the strongest degree raises the feebler related body up to a state of equality.

The neutral state which Dr. Faraday supposes to exist through the struggle of what he terms magnetic and diamagnetic forces, in various saline solutions, is according to the preceding views due entirely to the relative strength of the latent attraction or repulsion roused into a state of exaggeration, and if I may so say abnormalism, by the surpassing energy of the electro-magnet; but were we to suppose the phanomena thus exhibited to be the normal state of nature, we should interpret wrong, and mistake the exception for the rule.

But as facts are better than all reasoning, I proceed to exhibit the mutual attractions and presumed repulsions which I elicited in about 600 additional experiments, together with the measures so obtained.

The measturements of the experiments which follow were first thrown into a tabular form, the substances being arranged perpendicularly on the left side of the paper, and the needles in succession at the top, both of them being between ruled lines in opposite directions. This arrangement had the great advantage of affording an easy contrast at a glance, but notwithstanding the number of experiments that have been made it left too many lacuna, owing to the great number of needles and substances which I had not time to try; for the sake of saving space it was abandoned therefore for the present plan.

The needles employed are indicated by the letters which 
follow. The glass needle was of flint glass. It is possible that one of crown glass might have given even higher results; but if so its effects could not have been appreciable in the cases above $90^{\circ}$. By a reference to the counter experiments where crown and fint glass were the substances, and the metals the needles, there will be seen to be a great equality in the results.

M magnet; I iron; P. G. pure gold ; G18c. gold 18 carats ; $\mathrm{S}$ silver; $\mathrm{P}$ palladium ; $\mathrm{Pl}$, platinum ; Cad. cadmium; ' $\mathrm{T}$ tin ; L lead; Z zinc; Cop. copper; B brass; Germ. S. German silver; Ars. arsenic ; Gl. glass.

\section{1 st Class.}

Gold (pure) with $\mathrm{M} 90^{\circ}$, difficult; I $90^{\circ}+$; P. G. $90^{\circ}+$; G $18 \mathrm{c} .90^{\circ}$; P $90^{\circ}$; Pl. $81^{\circ}$; Cad. $90^{\circ}$ t. ; T $90^{\circ}+$; $\mathrm{Z} 90^{\circ}+$.

Gold (18 carats) with $\mathrm{M} 90^{\circ}$, difficult; I $90^{\circ}$; $\mathrm{T} 90^{\circ}+$; $B 90^{\circ} x$.

Silver (pure) with M $90^{\circ}+$; I $90^{\circ}+$; Cad. $90^{\circ}$; T $90^{\circ} \times$.

Silver (coin) with M $90^{\circ}+$; Cad. $90^{\circ}+$; ' $\Gamma 88^{\circ}$.

Palladium with $\mathrm{M} 68^{\circ}$; I $90^{\circ}+$; $\mathrm{P} 40^{\circ}$; Cad. $60^{\circ}$; T $90^{\circ}$.

Platinum with M $65^{\circ}$; I $90^{\circ}$; P. G. $86^{\circ}$; Pl. $75^{\circ}$; P $25^{\circ}$; Cad. $81^{\circ}$; T $82^{\circ}$; Gl. $90^{\circ}$ f. easy.

Cadmium with $\mathrm{M} 90^{\circ}$; Pl. $76^{\circ}$; after many efforts it would not come up to the $81^{\circ}$ of the cadmium needle and platinum; Cad. $90^{\circ}$, easy; $T 90^{\circ}$, very difficult.

Tin with $\mathrm{M} 90^{\circ}+$; $190^{\circ}$, but difficult; Cad. $90^{\circ}$, weak; $\mathrm{T} 90^{\circ}$, difficult at every step.

Lead with $\mathrm{M} 90^{\circ}+$; $190^{\circ}+$; P. G. $90^{\circ}$ f. very easy; Pl. $90^{\circ}$, easy; L $84^{\circ} ; \mathrm{Z} 90^{\circ}$, difficult; $\mathrm{B} 90^{\circ}$ f.; Gl. $90^{\circ}$ f. very firm.

Zinc with M $90^{\circ}$; Cad. $90^{\circ}$; $\Gamma 90^{\circ} \times$; L $90 \times$; Z $90^{\circ}$; Cop. $90^{\circ}$.

Copper with M $90^{\circ}+$; P. G. $90^{\circ}$ f. firm ; Pl. $90^{\circ}+$; ' $\mathrm{r} 90^{\circ} \times$; $\mathrm{Z} 90^{\circ}$; Cop. $90^{\circ}$; B $90^{\circ}$, f. firm.

Iron with $I 90^{\circ}$, very easy; ' $T 90^{\circ}$, rather difficult.

Mercury with M $90^{\circ}$, sticks; G. 18 c. $90^{\circ}$, sticks; 'T $76^{\circ}$.

Antimony with $\mathrm{M} 66^{\circ}$; I $27^{\circ}$; P. G. $90^{\circ}+$; Pl. $50^{\circ}$; Cad. $90^{\circ}$, very difficult; $\mathrm{T} 90^{\circ}$; Cop. $90^{\circ}$ f.; B $90^{\circ}$, firmish with the cut end.

Bismuth with M $51^{\circ}$; I $77^{\circ}$; P. G. 90 + ; Pl. $94^{\circ}$; Cad. $90^{\circ}$, difficult; T $90^{\circ}$; Cop. $90^{\circ}$; Gl. $90^{\circ}$.

Chromium with $\mathrm{M} 90^{\circ}$; at first it quite failed, but rose by waiting a very long space of time up to $90^{\circ} ; \mathrm{I} 60^{\circ} ; \mathrm{Pl} .90^{\circ}$; $T$ failed; L $36^{\circ}$.

Manganese with M. A.; Pl. failed; T $10^{\circ}$. 
Cobalt with $\mathrm{M} 90^{\circ}$; $\mathrm{T}$ failed.

Brass with $\mathrm{M} 90^{\circ}$; I $90^{\circ}$, not easy; P. G. $90^{\circ}$ f.; Pl. $90^{\circ}$; T $90^{\circ} \times$; L $90^{\circ}$, f. very ensy and firm; B. $90^{\circ}$, f. very easy, firm.

German silver with M. A.; P. G. $90^{\circ}$, f.; L $90^{\circ}$, f. very easy and firm; Cop. $90^{\circ}$, f. most easy; B $90^{\circ}$, f. strong; Gi. $90^{\circ}$, f. very strong.

Bell-metal with M $90^{\circ}$; P. G. $90^{\circ}$, f.; T $90^{\circ}$, junction easy after the use of the magnetic needle; L $90^{\circ}$, f. easy; Cop. $90^{\circ}$, f. firm; B $90^{\circ}$, f. very firm; Germ. S. $90^{\circ}$; Gl. $90^{\circ}$, f. easy.

Arsenic with $\mathrm{M} 15^{\circ}$; I $34^{\circ}$; P. G. $19^{\circ}$; S failed; P $34^{\circ}$;

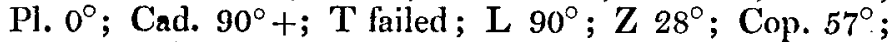
B failed; Germ. S. failed; Ars. $65^{\circ}$; Gl. $52^{\circ}$.

Plumbago with $M$ failed; I failed; Pl. failed.

In this and the following classes, the results already obtained with the magnetic needle are again repeated for the sake of affording an easy means of comparison. The iron needle was of soft iron wire, and on bringing it near a delicate magnetic needle it caused no repulsion, but attracted the $\mathrm{N}$. and S. poles; I therefore believe that if it had any magnetism it did not influence the results, and if so it would have had a tendency rather to diminish than to raise the measurements, for often, as in the case of palladium, platinum, bismuth and arsenic, iron has an advantage over the magnetic needle, though, as may be observed with regard to antimony and chromium, it often falls considerably behind it. Iron in its normal state, that is free from adventitious magnetism, discovers less affinity for other bodies, and even for itself, than gold, cadmium, tin, copper, and some other metals. When it was made to attach itself to a bit of its own wire, the connexion was broken with as much facility as was exhibited by most of the metals. This result will be scarcely anticipated, and is a further proof that it was devoid of free magnetism. The polarity that iron exhibits is due entirely to extraneous causes, and as my opinions have been long made up upon the subject, I hope before long to make them known, and to show that it depends upon causes of the simplest kind, if that expression may be applied to phænomena in which so mysterious an agency as affinity is concerned. Manganese exhibited only an attraction of $10^{\circ}$ for tin, and none for platinum. Chromium had likewise no attraction for tin, and indicated only $19^{\circ}$ for gold, while for platinum it had an attraction of $90^{\circ}$, yet both chromium and platinum are magnetic metals according to Dr. Faraday's experiments, and gold diamagnetic. But all 
these unexpected results will be seen at a glance by referring to the list.

Antimony and bismuth stand high with such non-ferruginous metals as have been tried; platinum, for which the attraction of both is low, being excepted. With cadmium the attraction for antimony was raised to $90^{\circ}$ by keeping the latter in contact with a bar-magnet for a shurt time; yet tin, between which and cadinium there is such a similarity, attained $90^{\circ}$ without being kept in contact with the bar-magnet; but $I$ see by a reference to the note taken at the time, that it was accomplished with some difficulty. It is remarkable that antimony was twice raised with the brass needle to $90^{\circ}$ with great ease, though before it could not be got higher than $30^{\circ}$. In the same way antimony was last year made to connect itself at $90^{\circ}$ with the copper needle, while now the cut end could only be got up to $40^{\circ}$, and the side to $55^{\circ}$, but this sort of capricionsness has occurred from time to time without any assignable cause.

\section{2nd Class.}

Selenium with M $10^{\circ}$; I $75^{\circ}$; P. G. $90^{\circ}+$; G. $18 \mathrm{c} .30^{\circ}$; P $20^{\circ}$; Pl. $39^{\circ}$; Cad. $90^{\circ}+$; T $90^{\circ}+$; L $35^{\circ}$; Z $90^{\circ}$; Cop. failed; B $63^{\circ}$; Ars. failed; Gl. $90^{\circ}$, f.

Sulphur with M $28^{\circ}$; I $39^{\circ}$ : P. G. $90^{\circ}+$; P $20^{\wedge}$; Pl. 65 ; Cad. $90^{\circ}$; T $90^{\circ}$; L $90^{\circ} \times$; Z $90^{\circ}+$; Cop. $90^{\circ}+$; B $65^{\circ}$; Gl. $90^{\circ} \mathrm{f}$.

What has already been said with regard to sulphur and selenium in the first part of this paper, leaves but little to be added. They will be found to show only a remarkable affinity for glass, but their contrast with lead is striking. The energy of both was heightened by being kept in contact with a magnet, and then tested with a brass needle. The preference that selenium shows for iron over the magnetic needle, is worthy of attention, as well as the contrast it stands in with sulphur, in its low attraction for lead.

\section{3rd Class.}

Diamond with $\mathrm{M} 65^{\circ}$; I $90^{\circ}$, not very difficult; G $18 \mathrm{c} .90^{\circ}$; Pl. $90^{\circ}$, f. strong; Cad. $90^{\circ}$, not easy; T $90^{\circ}+$; Z $90^{\circ}$; Cop. $90^{\circ}$, f. easy ; B $90^{\circ}+$; Gl. $90^{\circ}$, f. Ruby with $\mathrm{M} 90^{\circ}+$; $\mathrm{Cad} .90^{\circ}+$; $\mathrm{T} 90^{\circ}+$. Sapphire with M $90^{\circ}+$; Cad. $90^{\circ}+$; T $90^{\circ}+$. Topaz with $\mathrm{M} 74^{\circ}$; Cad. $75^{\circ}$; $\mathrm{T} 68^{\circ}$. Topaz (pale) with $\mathrm{M} 66^{\circ}$; Cad. $83^{\circ}$; $\mathrm{T} 80^{\circ}$. Jargoon with M $90^{\circ}+$; Cad. $90^{\circ}+$; $\mathrm{T} 90^{\circ}+$. Emerald with $\mathrm{M} 90^{\circ}+$; Cad. $90^{\circ}+$. 
Amethyst with $\mathrm{M} 65^{\circ}$; PJ. $90^{\circ}$, difficult; Cad. $90^{\circ} \times$; $\mathrm{T} 90^{\circ} \times$.

Opal with M failed; Cad. $90^{\circ}+$; T $90^{\circ}+$.

Cornelian (red) with $\mathrm{M} 35^{\circ}$; I $90^{\circ}$, f. very strong; P. G. $90^{\circ}$,

f. strong; $\mathrm{T}^{\circ} 90^{\circ}$, f. strong; $\mathrm{Z} 90^{\circ}$, f. strong; Cop. $90^{\circ}$, f. strong; Gl. $90^{\circ}$, f. very easy and strong.

Cornelian (white) with M $37^{\circ}$; I $90^{\circ}$, f. easy; P. G. $90^{\circ}$, f. strong; T $90^{\circ}$, f. strong; $\mathrm{Z} 90^{\circ}$, f. strong; Cop. $90^{\circ}$, f. strong; Gl. $90^{\circ}$, f. very easy and strong.

Blood-stone with $\mathrm{M} 37^{\circ} ; \mathrm{I} 90^{\circ}$, fo very easy; P. G. $90^{\circ}$, f. very strong; $\mathrm{T} 90^{\circ}$, f. strong; $\mathrm{Z} 90^{\circ}$, f. strong; Cop. 90, f. strong; Gl. $90^{\circ}$, f. very easy and strong.

Quartz with M $90^{\circ}$; PI. $90^{\circ}$, very easy; T $90^{\circ}$, $\mathrm{f}_{\mathrm{s}}$ strong; Cop. $90^{\circ}$, f. easy ; B $90^{\circ}$, f. firm.

Flint with $\mathrm{M} 90^{\circ} ; 190^{\circ}$, very difficult; P. G. $90^{\circ}$, f.; PI. $90^{\circ}$, not very firm; Cad. $90^{\circ}$; T $45^{\circ}$; L $90^{\circ}$, f. easy; B $90^{\circ}$, f.; Gi. $90^{\circ}$, f. very strong.

This class has been tested but to a limited extent with nonferruginous needles, but the results are sufficiently plain to prove that they follow the same law as the preceding classes, and there can be no doubt from the indications afforded by what have been tried, that they would have exhibited those strong affinities, belonging to all substances of the vitreous class. A second specimen of diamond, which was a mere spark, was tested with the magnet and iron, but the results were the same as with the first specimen. I am indebted for many of these specimens, to Messrs. Widdowson and Veale of the Strand, who very obligingly afforded me the use of them.

\section{4th Class.}

Flint glass (prism, English) with $\mathrm{M} 30^{\circ}$; P. G. $90^{\circ}$, f.; G $18 \mathrm{c}$. $73^{\circ}$, difficult; P $90^{\circ}$, f. ; Pl. $90^{\circ}, f_{\circ}$; Cad. $90^{\circ}$, f. ; T $90^{\circ}$, f. ; L $90^{\circ}$, f.; Z $90^{\circ}$, f. ; Cop. $90^{\circ}$, f ; B $90^{\circ}$, f.; Gl. $90^{\circ}$, f. Flint glass (tumbler) with M $90^{\circ}+; 190^{\circ}$, f.; P. G. $90^{\circ}$, f.; G 18c. $90^{\circ}$; P $90^{\circ}$, f.; Pl. $90^{\circ}$, f. ; Cad. $90^{\circ}$, f. ; T $90^{\circ}$, f. ; L $90^{\circ}$, f.; Z $90^{\circ}$, f. ; Cop. $90^{\circ}$, f.; B. $90^{\circ}$, f. ; Gl. $90^{\circ}$, f.

Crown glass with $\mathrm{M} 90^{\circ}$; I $90^{\circ}$, f. very easy and strong; P. G. $90^{\circ}$, f. not easy; G $18 \mathrm{c} .90^{\circ}$, very easy; P $90^{\circ}$, f.; Pl. $90^{\circ}$, f.; Cad. $90^{\circ}$, f.; T $90^{\circ}$, f.; L $90^{\circ}$, f.; Z $90^{\circ}$, f.; Cop. $90^{\circ}$, f. ; B $90^{\circ}$, f. ; Ars. $90^{\circ}$, f. most easy.

Blue glass with M $90^{\circ}+; 190^{\circ}$, f.; P. G. $90^{\circ}+;$ G $18 \mathrm{c} .85^{\circ}$; P 90 , f.; Pl. $90^{\circ}$, f.; Cad. $90^{\circ}$, f.; T $90^{\circ}$, f.; L $90^{\circ}$, f.; Z $90^{\circ}$,

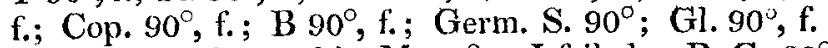

Green fancy glass with $\mathrm{M} 90^{\circ}$; I failed; P. G. $90^{\circ}, \mathrm{f}$; G 18c. $70^{\circ}$; P. $90^{\circ}$, f.; Pl. $90^{\circ}$, f.; Cad. $90^{\circ}$, f.; T $90^{\circ}$, f. ; 
L $90^{\circ}$, f.; Z $90^{\circ}$, f.; Cop. $90^{\circ}$ f.; B $90^{\circ}$, f. ; Germ. S. $90^{\circ}$, f.; Gl. $90^{\circ}$, very easy.

Red glass with P. G. $90^{\circ}$, f.; P. $90^{\circ}$, f.; PI. $90^{\circ}$, f.; Cad. $90^{\circ}$, f. very strong; $T 90^{\circ}$, f. very strong; $L 90^{\circ}, f_{1} ; Z 90^{\circ}, f^{\circ}$; Ger'm. S. $90^{\circ}$, f.

Green bottle glass with $\mathrm{M} 70^{\circ}$; P $90^{\circ}$, f.; Pl. $90^{\circ}$, f.; Cad. $90^{\circ}$, f.; T $90^{\circ}$, f.; L $90^{\circ}$, f. ; Z $90^{\circ}$, f. ; Cop. $90^{\circ}$, f.; B $90^{\circ}$, f.; Gl. $90^{\circ}, \mathrm{f}$.

Porcelain (French) with $\mathrm{M} 90^{\circ}$; P. G. $90^{\circ}$, f.; Pl. $90^{\circ}$; B 90 $0^{\circ}$ f. ; Gl: $90^{\circ}$, f.

Porcelain (dentist's) with M $74^{\circ}$; Pl. $90^{\circ}$, f.; L $90^{\circ}$, f.; $\mathrm{Z} 90^{\circ}, \mathrm{f}$.

Blue enamel with M $36^{\circ}$; T $90^{\circ} \times$.

Gypsum stone with $\mathrm{M} 26^{\circ}$; Gl. failed.

Alabaster with $\mathrm{M} 25^{\circ}$; Gl. $90^{\circ} \times$.

Marble (gray) with $\mathrm{M} 55^{\circ}$; G $18 \mathrm{c} .90^{\circ}$, difficult; 'T. $90^{\prime}$.

Marble (yellow) with M $10^{\circ}$; P.G. $90^{\circ}+$; G 18c. $56^{\circ}$; P $80^{\prime \prime}$; Pl. $90^{\circ}$; Cad. $90^{\circ}+$; T $90^{\circ}+$; Z $47^{\circ}$; Gl. $73^{\circ}$.

Gas coal with M $15 ;$ Gl. $0^{\circ}$.

Iceland spar with $\mathrm{M} 90^{\circ} ; \mathrm{I} 90^{\circ}+; \mathrm{P} . \mathrm{G} .90^{\circ}, \mathrm{f}$; G $18 \mathrm{c}$. $90^{\circ}$; S $90^{\circ}$, f. easy ; P $90^{\circ}$, f. ; Pl. $90^{\circ}$, f. ; Cad. $90^{\circ}$, f. ; T $90^{\circ}$, f. ; L $90^{\circ}+$; Z $90^{\circ}$, f. ensy ; Cop. $90^{\circ}$, f. firm; B $90^{\circ}$, f. strong; G]. $90^{\circ}$, f.

Felspar with $\mathrm{M} 10^{\circ}$; Cad. $30^{\circ}$; T $45^{\circ}$; Gl. $90^{\circ}$, f. very firm. Selenite with M $15^{\circ}$; P. G. $86^{\circ}$; T $85^{\circ}$; Gl. $90^{\circ}+$.

Talc with M. $60^{\circ}$; I $90^{\circ}+$; G 18c. $90^{\circ} ; \mathrm{Z} 40^{\circ}$.

Protosulphate of iron with M $90^{\circ}$, f. very easy; P. G. 90?, f. very easy; $\mathrm{Gl} .90^{\circ}$, f. very easy and strong.

Carbonate of iron with $\mathrm{M} 16^{\circ} ; 120^{\circ} ; \mathrm{P}$. G. $90^{\circ}$, f. rather difficult ; S 90 , f. firm; P failed; Pl. failed ; Cad. $90^{\circ}$, f. firm; T $90^{\circ}$, f. firm; L failed; Z $90^{\circ}$, f. most firm; Cop. $14^{\circ}$; B $14^{\circ}$; Germ. S. $9^{\circ}$; Gl. $90^{\circ}+$.

Sulphate of copper with GI. $90^{\circ}$, f. easy and strong.

Crystallized tin with $\mathrm{M}$ failed; I $90^{\circ}, \mathrm{f}$; $\mathrm{P} 90^{\circ}$, not difficult; Pl. $90^{\circ}$, difficult ; L $90^{\circ}$, f.; Z 90, f. contact instantaneous; Cop. $90^{\circ}$, f. ; B $90^{\circ}$, f. strong; Germ. S. $90^{\circ}$; Gl. $90^{\circ}$, f. contact instantaneous.

Alum with M $15^{\circ}$; Gl. $90^{\circ}$, f.

Rock salt with Gl. $90^{\circ}$, f. very strong.

Sugar candy (white) with P. G. $90^{\circ}+;$ T $90^{\circ}+$; Gl. $90^{\circ}$ f.

Sugar candy (brown) with Gl. $90^{\circ} \mathrm{f}$.

In this class it will be seen that iron in many cases maintains a great superiority over the magnet. The glasses seemed 


\section{2}

to deserve particular attention, and have been carefully tested. Their strong attraction for non-ferruginous bodies must prove interesting, and Iceland spar vies with them in that property, for the needles had only generally to be pushed against it to form the connexion. The porcelains exceed even the glasses in their affinities for non-ferruginous bodies. The attraction of glass for sugar candy, rock salt and alum, is worthy of attention. The metals were not tried, for want of time, with the exception of gold and tin.

The case of carbonate of iron is very remarkabie, for it might a priori be supposed that from the large proportion of iron it contains, it would show considerable attraction for the magnetic needle; but this is so far from being the case, that it will be seen to be one of the lowest in the scale, and after being kept eighteen hours in contact with the N. pole of a horseshoe magnet capable of raising thirty pounds, its affinity for the magnetic needle was not increased. It might also have been expected, from its great density, and the analogy of similar cases, that in consequence of its feeble attraction for the magnet, it would exhibit a strong affinity for glass. It however is otherwise; and by a reference to all the metals with which it was tested, in consequence of these peculiarities, it will be seen to be one of the most remarkable and interesting substances that have been tried, exhibiting a very low state of attraction for almost all bodies, gold, silver, cadmium, tin and zinc being excepted, and for these metals it exhibits a remarkable affinity. The results of many of the experiments on various bodies will show a kind of elective affinity, as is observed in chemical combinations; and no substance exemplifies this remark so completely as carbonate of iron. Thus though it has the strongest affinity for zinc, it does not show an attraction for brass above what it exhibits for copper, which is as low as $14^{\circ}$. Yet most bodies have a surprising affinity for brass. Carbonate of iron affords a fresh instance that the iron in a body may be quite inert, in consequence of its combination with another substance neutralizing its affinities.

The low affinity of the magnetic needle for marbles is quite in accordance with the experiments of Dr. Seebeck, and the numbers he obtained for bismuth, platinum and antimony, bear a singular resemblance to those afforded by the present experiments. There may be the same accordance between the others, but there is no means of marking by the present mode, the nice shades of difference after $90^{\circ}$. Silver, which he places next to iron in power, seems to take the place of brass, which $I$ find to be generally singularly magnetic. 
Amongst the alloys that become neutral by combination, be mentions copper and nickel; now this alloy, which is popularly called German silver, I believe, I found to be so magnetic as to draw the needle after it; but then the proportions of the two alloys most probably differed; his specimen contained two parts of copper and one of nickel, while mine, as I have already remarked, seemed to have an unusual proportion of copper, to judge from its colour.

\section{5th Class.}

Nacre with M $90^{\circ}$, f. firm; I $90^{\circ}$, f.; P. G. $90^{\circ}$, f. easy; $\mathrm{Pl} .90^{\circ}$, f. not very easy; T $90^{\circ}$, f. firm and easy; L $90^{\circ}$, f. firm; $\mathrm{Z} 90^{\circ}$, f. most easy ; Cop. $90^{\circ}$, f. firm ; B $90^{\circ}$, f. firm ; Ars. $90^{\circ}$, f. most easy ; Gl. $90^{\circ}$, f. most easy.

Ivory (oid) with $\mathrm{M} 58^{\circ} ; \mathrm{T} 48^{\circ}$; Gl. $58^{\circ}$.

Ivory (new) with $\mathrm{M} 90^{\circ}+$; $\mathrm{T} 90^{\circ}+; \mathrm{B} 90^{\circ}$, f. firm.

Enamel (human tooth) with $\mathrm{T} 90^{\circ}$.

Bone (mackerel's) with $\mathrm{M} 90^{\circ}$; Cad. $90^{\circ}$.

Whalebone with M $90^{\circ}$; I $90^{\circ}$; Cad. $90^{\circ}+$.

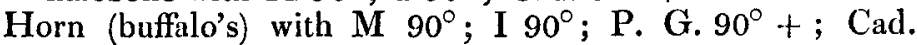
$90^{\circ}+$; $\mathrm{B} 90^{\circ}$, f. very strong.

Horn (cow's) with $\mathrm{M} 85^{\circ}$; I $90^{\circ}$; P. G. $90^{\circ}+$; Cad. $90^{\circ}+$; $B 90^{\circ}$, f. not very firm.

Horn (chamois') with $\mathrm{M} 90^{\circ} ; \mathrm{B} 90^{\circ}$, f. not very firm.

Albumen with Gl. $90^{\circ}$ f., strong.

Indian ink with $\mathrm{M} 70^{\circ}$; $\mathrm{Cad} .90^{\circ} ; \mathrm{L} 90^{\circ}+$.

Amber with $\mathrm{M} 75^{\circ}$; Cad. $90^{\circ}$; T $90^{\circ}$.

Gas coal with M $15^{\circ}$; Gl. 0 .

Glue with M $29^{\circ}$; I $90^{\circ}+$; P. G. $90^{\circ}$, difficult; P. $90^{\circ}+$; Pl. $90^{\circ}+$; Cad. $90^{\circ}+$; T $90^{\circ}+$; Z $90^{\circ}+$; Gl. $90^{\circ}+$ ?

Pig's bristle with T failed.

Cat's whisker with M $90^{\circ} \times$; I $90^{\circ} \times$; G 18c. $90^{\circ} \times$; Cad. $90^{\circ} \times$; T $90^{\circ} \times$; L $90^{\circ} \times$; Z $90^{\circ}$, difficult ; Cop. $90^{\circ} \times$.

Human hair (brown, male's) with $\mathrm{M} 90^{\circ}$; 'T $90^{\circ}$.

Human hair (female's) with $\mathrm{M} 80^{\circ}$; $\mathrm{T} 90^{\circ}+$.

Human hair (female's, 2nd specimen) with $\mathrm{M} 76^{\circ}$; $\mathrm{T} 90^{\circ}+$. Human hair (gray, male's) with $\mathrm{M} 90^{\circ}+$; $\mathrm{T} 50^{\circ}$.

Human hair (gray, female's) with M $90^{\circ}+;$ ' T $90^{\circ}$. Human hair (beard, gray) with $\mathrm{M} 90^{\circ}+$; Cad. $90^{\circ}$. Horsehair (gray) with M $90^{\circ}$; $\mathrm{T} 90^{\circ}$.

Horsehair (black) with $\mathrm{M} 90^{\circ}$; $\mathrm{T} 90^{\circ}$.

In this class of animal products the magnetism of the needle is tolerably strong, while that of the other bodies is still more remarkable. The specimen of ivory (a paper-cutter), which could not be less than thirty old years since the time of its importation, only exhibited $58^{\circ}$, but was raised to $74^{\circ}$ by contact Phil. Mag. S. 3. No. 204. Suppl. Vol. 30. 


\section{Sir G. C. Haughton on the Common Nature of}

with a magnet; while the second specimen, which was comparatively recent, as was evident from its fine colour, gave $90^{\circ}$ with the magnetic needle; and the probable cause of this difference will be shortly seen, when 1 speak of the results obtained with a needle made out of a part of this very piece of ivory. Glue exhibits phænomena of a very interesting character. Its affinity for the magnet was only $29^{\circ}$, after the most painful efforts were repeatedly made to push it further, but on being left in contact with the bar-magnet for some hours, it instantly attached itself at $38^{\circ}$. Its affinity for the iron was $90^{\circ}+$, and it exhibited the same amount of attraction for pure gold, platinum, cadmium, tin, zinc and arsenic, which were all the metals it was tested with. But I have some doubts about all the high measurements, as I fear that the dampness of the weather may have influenced the results, though the different specimens appeared perfectly hard.

\section{7th Class.}

Jeal wood with $\mathrm{M} 30^{\circ}$; $\mathrm{T} 30^{\circ} ; \mathrm{B} 90^{\circ}$, f.

Box wood with $\mathrm{T} 15^{\circ}$.

Rose wood with T $90^{\circ}$.

Oak with $I 90^{\circ}$, very difficult; $\mathrm{B} 90^{\circ}$, f.

Lignum vitæ with M $33^{\circ}$; I $18^{\circ}$; Cad. $22^{\circ}$; T. $90^{\circ}$; L $90^{\circ}$. Cedar wood with $\mathrm{M}$ failed; $\mathrm{B} 90^{\circ}+$.

Vegetable ivory with $\mathrm{M} 56^{\circ}$; I $67^{\circ}$; G $18 \mathrm{c} .90^{\circ}$; Cad. $90^{\circ}+$; $\mathrm{T} 90^{\circ}$, very difficult.

Vegetable ivory (2nd specimen) with M failed; I $50^{\circ}$; P. G. $90^{\circ}$, f. firm; L $80^{\circ}$; Z $90^{\circ}+$; Cop. $90^{\circ}+$; Gl. $90^{\circ}$, f. strong. Vegetable ivory (3rd specimen) with $\mathrm{M}$ failed; $\mathrm{I} 70^{\circ}$. Mahogany with B $90^{\circ}$, f.; Gl. $24^{\circ}$.

Lac (pure) with M $35^{\circ}$; P. G. $90^{\circ}$; G 18c. $74^{\circ}$; Cad. $90^{\circ}$; T $90^{\circ}+$; L $90^{\circ}$; Cop. $65^{\circ} ;$ Gl. $90^{\circ} \mathrm{f}$.

Sealing-wax (black) with $\mathrm{M} 25^{\circ}$; I failed; T $70^{\circ}$.

India rubber with $\mathrm{M} 80^{\circ}$; $\mathrm{Cad} .90^{\circ}+$.

India rubber (bottle) with P. G. $70^{\circ}$; B $90^{\circ}+$; Gl. $50^{\circ}, \mathrm{f}$.

Resin with $\mathrm{M} 90^{\circ}$; $\mathrm{T} 90^{\circ} \times$; Gl. $48^{\circ}$.

Gum with Gl. $90^{\circ}+$.

Macaroni with Gl. $40^{\circ}$.

Dry paste on paper with M failed; Gl. $23^{\circ}$.

The peculiarity connected with the attraction of lignum vitæ and vegetable ivory for the magnet and other substances is remarkable. The lignum vitæ was raised from $33^{\circ}$ to $49^{\circ}$ by contact for a short time with a magnet, and the same process raised it from $18^{\circ}$ to $30^{\circ}$ with iron, while with tin and lead it had exhibited $90^{\circ}$, and only $22^{\circ}$ are marked for cad- 
mium. Three specimens of vegetable ivory were tried on many occasions with great care, and the results they afforded were always uniform, but differed from one another. The first specimen gave $56^{\circ}$ with the magnetic needle, but the two others failed altogether. On two or three occasions the magnetic needle connected itself with one of the specimens that had previously failed, after it had been kept in contact with a magnet; but I cannot positively say that the magnet was the cause, as on repeating the same experiment on other occasions, no such result took place; still the needle did not connect itself till after the attempt to raise its magnetism, though many trials had previously been made. The attraction of iron for all three specimens is deserving of notice. This singular substance exhibited a strong affinity for all the needles with which it was tested. The affinity of lac for various metals and substances, including glass, is worthy of attention. Sealingwax and India rubber of the bottle kind exhibit a strong affinity for many non-ferruginous bodies.

I have thought that it would be useful to sum up all the preceding results, in such a way as to exhibit their relative affinities; and with this view they have been thrown into the following tabular form, which though it does not contrast cases altogether analogous, because the substances the needles were tried with were not always the same, still some general inferences may be drawn from them, not devoid of interest.

Results of the Measurements.

\begin{tabular}{|c|c|c|c|}
\hline Substances. & $90^{\circ}$ and above. & Under $90^{\circ}$. & Failed. \\
\hline Magnet............. & 51 & 54 & 10 \\
\hline Iron ................... & 25 & 8 & $\mathbf{3}$ \\
\hline Pure gold........... & 24 & 3 & 0 \\
\hline Gold, 18 carats... & 12 & 5 & 0 \\
\hline Silver............... & $\mathbf{5}$ & 1 & 1 \\
\hline Pallatium.......... & 13 & 6 & 1 \\
\hline Platinum ........... & 21 & 7 & 3 \\
\hline Cadmium ........... & 33 & 7 & 0 \\
\hline Tin................. & 43 & 9 & $\mathcal{Z}$ \\
\hline Lead ................ & 21 & 4 & 1 \\
\hline Zinc................ & 20 & 3 & 0 \\
\hline Copper .............. & 23 & 3 & 0 \\
\hline Brass................. & 30 & 2 & 0 \\
\hline Glass............... & 38 & 5 & 2 \\
\hline Total..... & 360 & 117 & 23 \\
\hline
\end{tabular}

If the relative affinities thus elicited conld be dependerl upon, the substances would be arranged as follows, and their $2 \mathrm{M} 2$ 
relative intensities would be according to the ratio assigned to each :-

\begin{tabular}{|c|c|}
\hline $16 \cdot 00$ & $5 \cdot 144$ \\
\hline Pure gold...... 900 & .... 4.909 \\
\hline Copper.......... 8.33 & $\ldots .3 \%$ \\
\hline Zin & Gold, 18 \\
\hline $6 \cdot 4$ & Platinum......... 3•100 \\
\hline$\ldots 6 \cdot 666$ & Palladium.. \\
\hline Cadmium. & Mignet. \\
\hline
\end{tabular}

To judge by the facility with which the needles attached themselves, brass is undoubtedly worthy of the high place it maintains in the preceding list; but 1 should certainly say from my own convictions, that glass is much stronger in its adhesions than even pure gold, and perhaps equal to brass. The advantage that iron has over the magnetic needle is conspicuous, and is deserving of attention, though the ratio of the magnet might very fairly be raised to $2 \cdot 00$, for it is in part owing to the experiments with the larger range of substances, that it stands so low.

The preceding experiments include a vast variety of substances in the mineral, vegetable, and animal kingdoms, that exhibit such strong attractive affinities for one another, that however much they may differ in their external appearances, and in their very natures, they are bound together by common bonds that connect them all into a single family; for we find the metal attaching itself to crystalline, animal and vegetable substances; and again, the crystal, whether we call it by the name of diamond, salt, or sugar-candy, connecting itself readily to metallic, animal and vegetable bodies. In a similar way animal bodies attach themselves to those that are mineral and vegetable; and to complete the circle, the vegetable kingdom, by its woods, its gums, its lac and its resins, is connected with them all.

Out of about 600 measurements the proportion of those that have exhibited repulsion, or what may be presumed repulsion, for there is only negative proof on the subject, is about 1 in 25 . Could a counter system of measurements be established it is possible this might be reversed, and that the same amount of repulsions would be obtained, and this perhaps is the fact in Dr. Faraday's remarkable experiments, owing to the influence of the electro-magnet. Still the facility with which the majority of these connexions was established, can hardly lead to a doubt that they are purely of a normal character, where the magnetic needle is not concerned, because they can only result from the spontaneous effects of 
nature; but in the case where the magnetic needle has been the coercing agent, and the measures indicate low intensities, and where the connexion was made with much difficulty, I should draw a contrary inference. This view is strongly supported by what took place with the cornelians.

The two extremes of the preceding scale give two alloyed metals as the highest and the lowest, namely, brass and the magnet. In seeking for two unmixed bodies that should properly represent the natural scale in the mineral kingdom, that is, one in which the magnetic needle is not arbitrarily assumed as the standard of reference, but one that considers the natural classes of substances, I would prefer taking platinum and diamond, and exclude brass and the magnet. The first would take the lead of all metals, namely metalloids, while diamond would be placed at the head of all substances of the vitreous class, or haloids, that is to say, all the precious stones and all crystals; platinum as the heaviest, and diamond as the hardest of all known bodies. The class of metalloids will be as naturally closed by potassium, as it will be seen the haloids are by gum, two of the lightest of the metallic and vitreous classes of bodies. The reason for adopting this classification is, that $I$ find that iron, from which the magnet is formed, has no remarkable affinity for other bodies, nor for itself, and that the magnet, constituting an exception to the rule of nature, is itself dependent for its exalted effects upon electricity and other extraneous causes, and could only keep its high position while attractive affinity, by our ignorance of natural laws, was supposed to be exclusively its peculiar property. Such a division is by no means meant to undervalue the importance of the magnet; for though it has led to the discovery of the affinities of all the rest, there can be no doubt it exists by an exceptional law; and we might as well place iron at the head of all metals, because we are indebted to it for the implements which have enabled us to penetrate to those very metals. The term magnetism therefore will always maintain its ground as the general expression of the magnetic attractions which connect all bodies together, even though they have nothing to do with iron; in the same way that the term electricity has been extended to all those phænomena in which attraction or repulsion result from friction, and yet having not the slightest resemblance to the electron or amber that led to their discovery.

In the mineral kingdom, metallic and crystalline bodies form the mass of its constituents, and they generally stand clearly contrasted with one another; yet platinum as well as diamond, and all vitreous substances, have a remarkable affi- 


\section{Sir G. C. Haughton on the Common Nature of}

nity for other bodies; and if we fix upon a metallic and vitreous type, no two substances are more entitled to be considered as the chiefs of their respective classes; and if platinum had not been known, gold would have taken its place; when those two precious bodies, gold and diamond, that have been so long conjoined in the associations of mankind, would still have maintained their rank.

Such are the views I am led to entertain of universal magnetism, that is of magnetism, cohesion, adhesion, and viscosity. And what is viscosity but the employment of a watery vehicle, which is afterwards to disappear, partly through the effects of heat, but mainly through its greater affinity for air and other substances which are said to absorb it, if inwards, by vessels, through what is called endosmosis, and if outwards, exosmosis? This fluid helps to hold together gelatinous, albuminous and glutinous substances, in such a manner as to bring all their particles into close connexion with themselves, as well as with the bodies to which they are to be attached, and thus by expelling air from between them all, brings every portion into close contact, when, the fluid part having disappeared, the whole is converted by exsiccation into a concrete mass through the power of the affinities of which we have just had so many examples. In the same manner bodies like lac, resin, pitch, \&c., that only require the application of heat to become liquid, are enabled to mould themselves to the inequalities of the bodies upon which they are dropped, and thus making counter-impressions connect themselves with a force proportioned to their surfaces, that is to say, of the collection of points of which these are composed. What too is the water that generally forms the vehicle in the former cases, but a crystal or salt called ice (oxide of hydrogen) liquefied by heat, and of such universal strength of affinity while fluid, as to connect itself with nearly every body it touches, which it is then said popularly to wet, and that too in a degree always in proportion to the quantity of caloric it contains at the moment, those substances being excepted between which and it there exists such a decided repugnance, that they exhibit a repulsion that nothing can overcome, but the union of a third body that neutralizes both, and which we see exemplified in water, grease, and soap? Is it desired to strengthen the adhesiveness of gelatinous and albuminous bodies? we then have recourse to a fluid still more powerful than water, to one that has a still stronger affinity for these substances, and we substitute alcohol, the result being a compound of such tenacity that it is considered as a cement; and such is the affinity of alcohol for other bodies that it is employed to clear away, or 
to speak more philosophically, to dissolve the film of particles that covers object-glasses and nirrors so rapidly, owing to the affinity or magnetism that all bodies possess for one another, and which the astronomer and the optician unconsciously heighten by the very means to which they have recourse, as the particles that float in the air again attach themselves with increased facility by the use of the alcohol. In a similar, but reverse sense, water will not attach itself to many metals, but if they are kept in a horizontal position, the fluid, in its attempt to shrink away, will collect itself up into little drops as if the surface were greasy, and it is only prevented from flying away by its density, which condemns it to obey the law of gravitation. This repugnance of water for metals I consider to be the main cause why dew does not settle upon them, when neighbouring bodies are completely covered by it.

I had arrived at the preceding convictions, when a discovery I made excited in me a degree of surprise that will, I doubt not, be felt by others. Having formed a needle of the fresh specimen of ivory which I have already mentioned, I was tempted some days afterwards, by a movement almost of idle curiosity, as I had just succeeded with one of sealingwax against glass, to test it also with the same substance, when I found that by a mere push of the finger, it attached itself firmly to it. In consequence of this most unexpected result, the ivory needle was tried with all the following substances, and it succeeded in every case at $90^{\circ}$ by the mere use of the finger, except with those preceded by an asterisk, for which the magnet was obliged to be employed, and therefore their intensities must be considered a shade lower than those of the other's, as well as a few that were lower still, but which have their measurements assigned.

rold.

Silver.

Palladium.

Platinum.

Cadmium.

Tin, $49^{\circ}$.

Bismuth, $76^{\circ}$.

Lead, $81^{\circ}$.

*Zinc.

Copper.

Brass.

Bell-metal.

German silver.

Sulphur.

Selenium.

Diamond.

Opal.
Cornelian.

Flint.

Marble.

Alabaster.

Flint glass.

Crown glass.

Plaster of Paris (stone) $37^{\circ}$.

Stone-ware.

Porcelain (French).

Ditto (dentist's).

*Felspar.

* Sulphate of copper.

* Carbonate of iron.

Crystallized tin.

Iceland spar.

Talc.
Rock salt.

Horn (cow's)

Ditto (buffalo's).

*Ivory (old).

Ditto (new).

Albumen.

Glue.

Nacre.

Vegetable ivory.

Ditto (2nd specimen).

Indian ink.

Lac.

Resin, $75^{\circ}$.

*Gum.

'The ivory needle would not connect itself with gypsum, arsenic and antimony, and indeed when the coercing magnet 
was withdrawn from the latter, the needle seemed always to set off with more than usual haste, as if strongly repelled, but no symptom of repulsion was exhibited when the ivory was brought near the magnetic needle standing in repose.

Here was a curious problem to be solved. What was the cause of this extraordinary affinity of a substance like ivory for so many heterogeneous bodies, of which porcelain offered the most remarkable instance, as the specimen employed, which stood on a surface of glass, drew the ivory as much as one-fourth of an inch after it on one occasion, and always some small distance when it was merely pushed away? The diamond exhibited the same phænomenon, but in a minor degree, and careful testing proved that electricity in no way contributed to the results.

On referring to the tabulated measurements of which I have spoken, and in which the measures of substances stand in ready contrast; I observed that the needles had attached themselves with remarkable facility to animal bodies, such as ivory, pearl, mother-of-pearl, horn, hair, glue, \&c. It was evident, therefore, that it was the affinity of something common to all these substances, that caused such easy contact between them and the needles. This step gained it was not difficult to discover that the gelatine which was common to all these animal products, was the substance that chiefly produced with equal facility a contact with gold, diamond, Iceland spar, marble, alabaster, horn, vegetable ivory, gum, and such dissimilar substances, in the mineral, vegetable and animal kingdoms. The low attraction afforded by the piece of old ivory of which I have spoken, I suppose to have resulted from partial change in its structure through age; and the same cause may be assigned for the difference exhibited by the pearl and the mother-of-pearl in their measures, for from the colour and the style of setting of the pearl, less than fifty years could not be assigned for its workmanship.

I have already alluded to the facility with which all vitreous bodies form connexions, and to include the present class of substances in their proper category, we must get rid a little of our familiar notions, and remember that if gelatine, albumen, gluten, resin, lac and gums are devoted to particular uses that make us only think of them as means of adhesion, they are in fact, when considered under a more extended point of view, animal and vegetable glasses; and what fully establishes this character is the extraordinary fact which I have already mentioned, that glue was raised to $38^{\circ}$ by contact with a barmagnet; but in truth since that portion of this communication was despatched for the press, the piece of glue was raised to 
$78^{\circ}$ by being kept in contact for four-and-twenty hours with the great horse-shoe magnet already spoken of, and the mag. netic needle attached itself with singular readiness, contrary to what had been previously found to be the case. The whole effect however gradually disappeared, the attractive power declining, as was ascertained by successive measurements, till it fell back to its normal state of $28^{\circ}$, in about twenty minutes. It was by mere accident, as may be supposed, that it was kept so long in contact, and most likely so long a time is not necessary to produce the effect*. This result is wellworthy of being contrasted with what has been said about carbonate of iron, and it will be admitted, I am sure, that two cases less reconcilable with analogy could scarcely be produced. We thus see that gelatine, and in all probability similar substances, conform to the laws that have been seen to prevail in vitreous bodies, and it is only necessary to observe their fractured edges when hard, and particularly those of glue, dried albumen and resin, to be convinced of this fact. Even India rubber when in a low temperature approaches to the same state, and it has been already noted that several needles attached themselves firmly to it. To be convinced that this view, which connects these substances with the glasses, is not fanciful, it is only necessary to call to mind the case of gelatinous hydrate of silicium, which is obtained from a mineral glass that dissolves in water; and it is not amongst the least remarkable of the analogies that exist throughont nature, to connect the liquor of flints with broth, white of egg, gum water and paste, and the last of these therefore, by a series of links, with the mysterious powers of the magnet, that caused St. Augustin to faint, and made Thales to believe that it was animated by a soul!

To be quite convinced of the strong affinities that ivory, mother-of-pearl, horn, albumen, tortoise-shell and quill exhibit in common, I formed needles of these substances, and tested them to an extent that left no doubt that they possess the same qualities as ivory; but on the whole the quill and mother-of-pearl approached nearest to a state of equality with that substance, though there was a very slight difference between them all. These fresh proofs leave therefore no

* It has since however been ascertained that length of time was essentially the cause of raising the magnetism of the glue, for on keeping it subsequently in contact for thirteen hours, its magnetism could only be raised to $49^{\circ}$. Another very important point was likewise fully established, namely, that either pole of a magnet might be used without the glue showing any signs of polarity, for when $78^{\circ}$ were obtained it had been kept in contact with the $\mathrm{N}$. end of the nagnet, and when $49^{\circ}$ was the amount of measurement the $\mathrm{S}$. end was emplcyed, while in each case it was the $\mathrm{S}$. end of the needle that formed the connexion. 


\section{On Magnetism, Cohesion, Adhesion and Viscosity.}

doubt that it is owing mainly to the gelatine they contain, that these needles show such a remarkable degree of attraction for nearly all bodies.

I do not mean to say that all cohesion is purely magnetical in the extended sense $I$ have given to the term, for such an opinion is scarcely reconcilable with what is observed in chemical combinations, where we see elements changing places according to what is called elective affinity. In the various theories that have been put forth to accouni for chemical combinations and the cohesion of bodies, the attractions and repulsions of different electrical states have been proposed by the celebrated Berzelius; but though this might, as a theory, obtain currency amongst scientific men, and enable them to reason with facility, as long as acids and their bases are considered, yet it is clearly in fault the moment it is applied to explain the cohesion of simple bodies, such as the pure metals. Many instances may be observed in the preceding experiments, that favour the notion of the existence of elective affinity between the various bodies that have been experimented upon, but to which immediate electric agency can with difficulty be conceded; and we must therefore have recourse in such cases to what are called the laws of nature for their explanation. With regard however to the combinations of acids and alkalies, I believe the varying preferences they exhibit when brought near one another to result from electricity, though magnetism is not without its share in effecting their union; and I hope shortly to be able to present some considerations that will render this opinion highly probable, by making known a discovery I have made of the antagonism of heat and electricity, as well as the proofs of a single electric fluid.

I cannot take leave of this subject without expressing my unfeigned admiration for the skill exhibited by Dr. Faraday, in his experiments on the same subject, as well as on so many other occasions; and if we differ in our views of magnetical phænomena, it will be easily accounted for, by the opposite results we have obtained, owing to our methods of experimenting, and the greater range and variety of observations that the present one has given birth to, over those recorded by that eminent experimenter.

I hope that the state of my health, which has compelled me to dictate this communication, and which has prevented me from giving it the benefit of after-perusal, will be accepted as a sufficient excuse for any oversights that may be observed.

Paris, 15, Rue de Tournon, 19 th May, 1847. 